Nr $258 \bullet 1996$

Young drivers' overestimation of their own skill - An experiment on the relation between training strategy and skill

Nils Petter Gregersen

Reprint from Accident Analysis \& Prevention, Vol. 28, No. 2, pp. 243-250, 1996

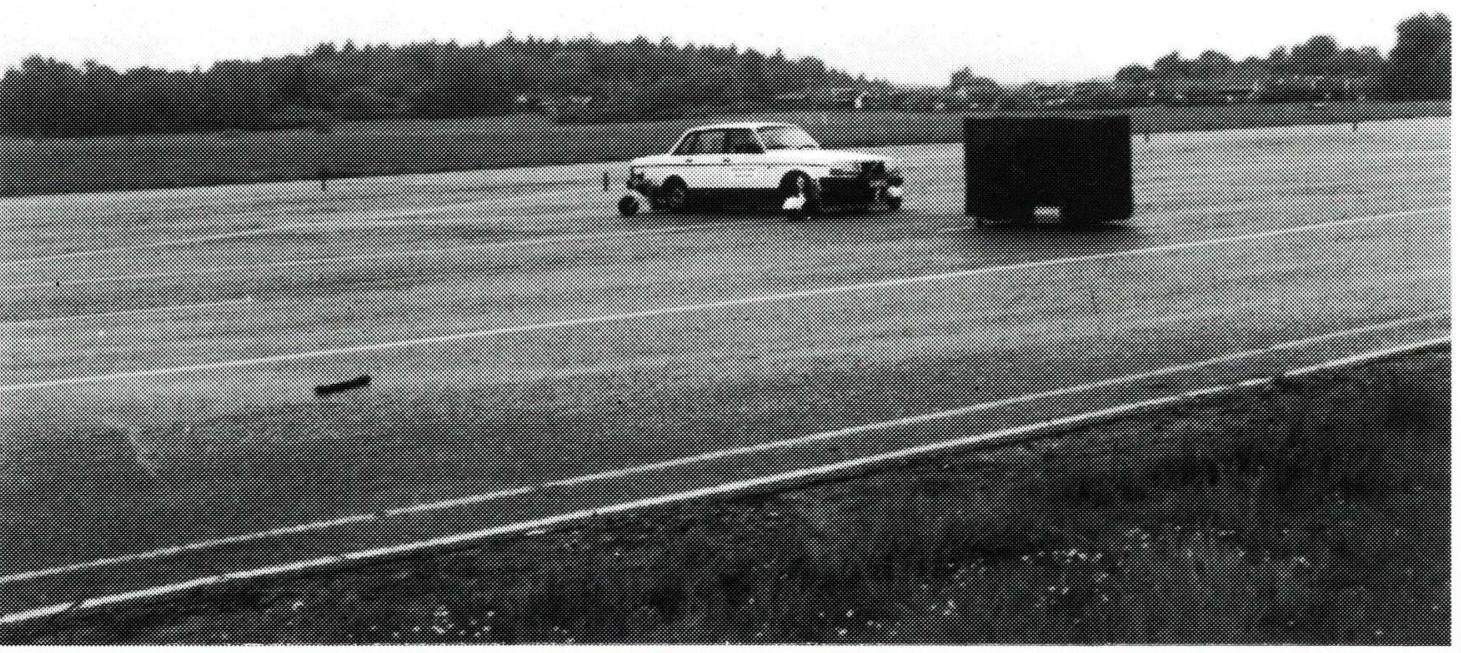

ds 



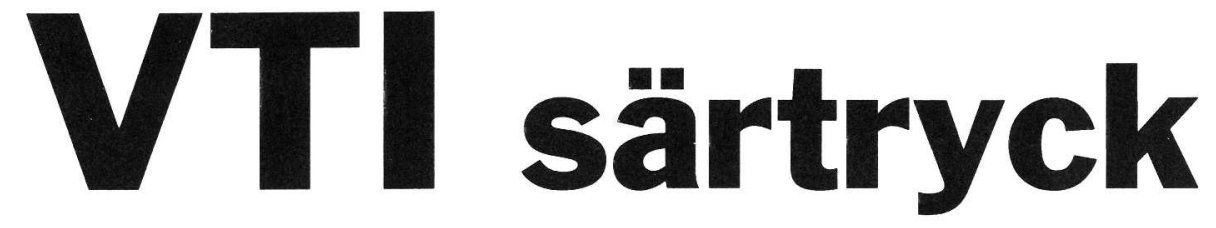

$\operatorname{Nr} 258 \bullet 1996$

Young drivers' overestimation of their own skill - An experiment on the relation between training strategy and skill

\section{Nils Petter Gregersen}

Reprint from Accident Analysis \& Prevention, Vol. 28, No. 2, pp. 243-250, 1996 
Samhall Brahe AB, Grafiska Linköping 1996 


\title{
YOUNG DRIVERS' OVERESTIMATION OF THEIR OWN SKILL-AN EXPERIMENT ON THE RELATION BETWEEN TRAINING STRATEGY AND SKILL
}

\author{
NiLs Petter Gregersen \\ Swedish Road and Transport Research Institute (VTI), S-581 95 Linköping, Sweden and Department of \\ Community Medicine, University of Linköping \\ (Accepted 20 August 1995)
}

\begin{abstract}
Young drivers' accident involvement may be explained by a number of different factors, one of which is that they tend to overestimate their skill in driving a car. This study is based upon the assumption that the degree of overestimation is related to the type of training the driver has received. In an experiment, two different strategies for training have been compared with regard to their influence on estimated and actual driving skill, as well as the drivers' degree of overestimation of their own skill. One of the strategies, used in the "skill" group was to make the learner as skilled as possible in handling a braking and avoidance manoeuvre in a critical situation. The other strategy, used in the "insight" group was to make the driver aware of the fact that his own skill in braking and avoidance in critical situations may be limited and unpredictable. The experiment was carried out at the Bromma driving practice area in Stockholm. Low friction has been simulated by using "Skid Car" equipment. Fifty-three learner drivers were randomly divided into two groups. Each of the groups was taught on the basis of one of the strategies. The training session was 30 minutes long. One week later, the drivers returned to take part in a test of their estimated and actual skill. The "skill" group estimated their skill higher than the "insight" group. No difference was found between the groups regarding their actual skill. The results confirm the main hypothesis that the skill training strategy produces more false overestimation than the insight training strategy.
\end{abstract}

Keywords-Recently qualified drivers, Safety, Driver training

\section{INTRODUCTION}

Many factors contribute to the accident involvement of young drivers. Some are related to experience and skill, while others are connected with age, lifestyle etc. In Gregersen and Bjurulf (1996) the most important factors were discussed in a model of young drivers' driving behaviour.

The model describes how the learning process as well as social and personal factors are related to cognitive aspects of self assessment, risk evaluation, information processing and motivation, and how driving behaviour is influenced by these processes. The model includes several well established theories concerning driving behaviour, such as risk compensation, automation and cognitive load (Fig. 1).

\section{Subjective skill}

In this article, the part of the model that describes the relation between learning and objective/subjective skill is analysed further.

It has been shown in several studies that young drivers overestimate their driving skill. They regard themselves as being more skilled than other, more experienced drivers. The most common method of measuring self-assessment has been to use questionnaire studies. The drivers are asked to estimate their ability compared to other drivers (Svenson 1981; Spolander 1983; Moe 1984; Matthews and Moran 1986; Gregersen 1993; McGormick et al. 1986). Traditionally, this type of study has shown that young drivers consider themselves superior to other drivers. The pattern has also been shown to be most prevalent among young men.

Finn and Bragg (1986) found that young drivers estimate their own probability of being involved in an accident as lower than other young drivers, as well as other drivers in general, in spite of their general view that the accident risk for young drivers is higher. A similar pattern was shown by Matthews and Moran (1986) who showed that young drivers consider themselves more skilled than other drivers, whether young or old. Older drivers, however, consider themselves equally skilled to other drivers in their own age, but superior to young drivers. 


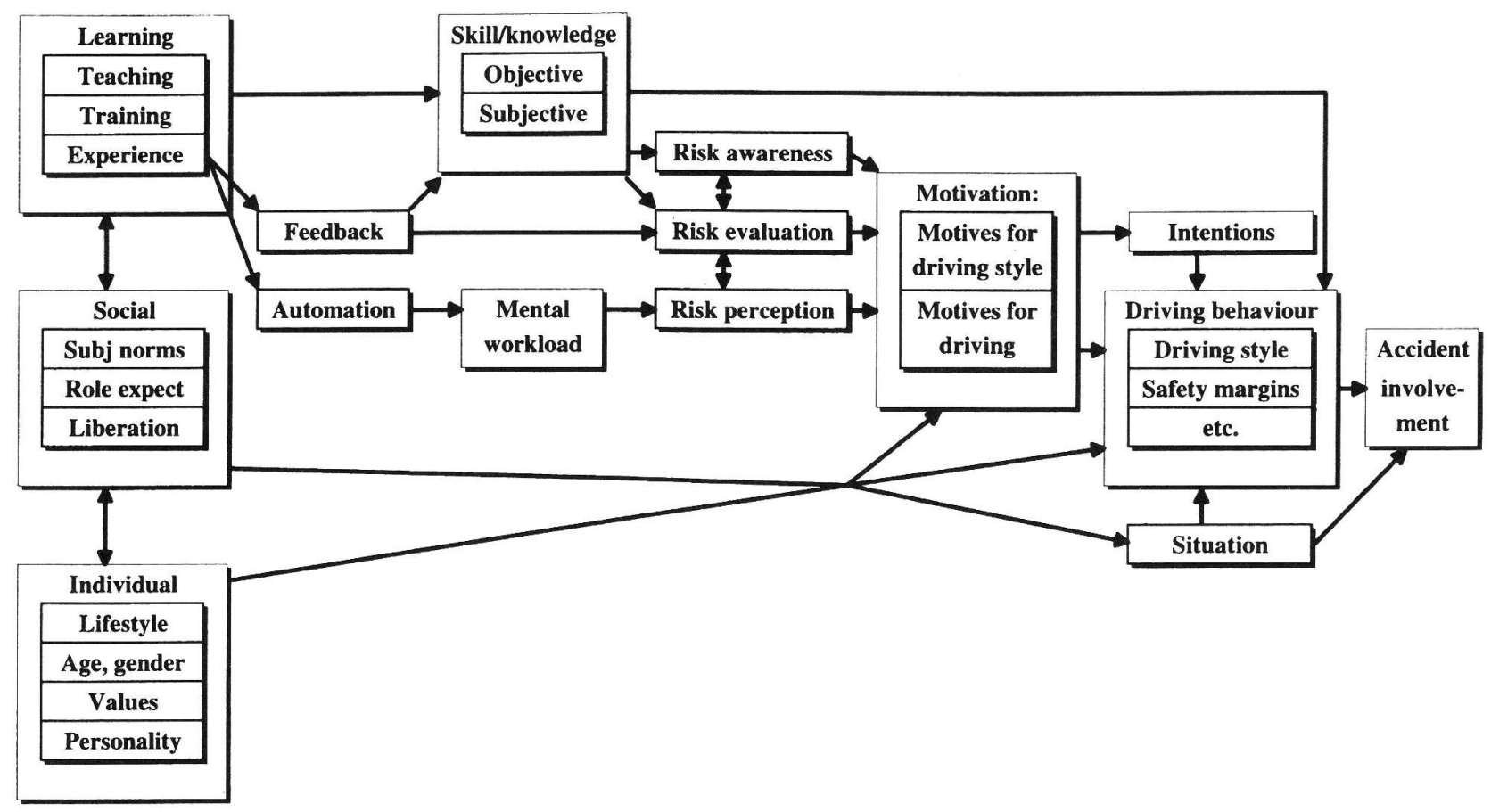

Fig. 1. Model of young drivers' accident involvement.

The conclusion drawn in these studies is that young drivers are poor at estimating their own ability and thus at estimating risks adequately. They underestimate the risks and overestimate their skill as drivers. It is obvious that there is a relationship between estimated risk and estimated ability. If a driver believes that he is a skilled driver able to handle a dangerous situation, the situation is not interpreted to be as dangerous as it would be by a driver who underestimates his skill. In the Benda and Hoyos (1983) study, this phenomenon is shown by the risk evaluation of situations on photographs. Situations with a high level of information load were classified as less risky. From an educational point of view, these findings are complicated, since the drivers are not motivated to drive more carefully than they believe is necessary. The findings also make analysis complicated since a probable outcome may be that the drivers reject theoretical information about risks with explanations such as "It is only a problem for others, not for me since I am so clever". Several studies have shown that young drivers choose to behave more unsafely (Jonah 1986). They drive faster (Wasielewsky 1984; Wilde 1982; Galin 1981; Koneci et al. 1976; Michels and Schneider 1984; Quimby and Watts 1981). They also drive in ways that increase the probability of conflicts with other drivers. Evans and Wasielewsky (1983) showed that they drive with smaller gaps, which is supported by Lalonde (1979) who showed that young drivers are involved in more rear-end collisions. Young drivers also use safety belts less often (Nolén 1988; Lacko and Nilsson 1988; Fhanér and Hane 1973; Evans et al. 1982; Wilson 1984).

In a study by Moe (1986a) subjective and objective ability have been compared. He compared an "internal model" of driving ability from a questionnaire study with results from a behavioural study and found a high degree of correspondence between the distributions in the studies. In a second study, he stopped drivers after measuring their speed on a certain road. The results showed that young men in the high speed group believed themselves to be significantly more skilled than the low speed group. This obvious difference was not found among women or older men.

A general conclusion from all these findings is probably that drivers' overestimation of their own skill contributes to higher accident involvement. The problem of overestimation also seems to be higher among young drivers. An important method of improving safety among young drivers may therefore be to find ways of making them realize their own limitations and understand that situations very well may occur that they cannot handle.

\section{Training strategies}

Traditionally, one of the most important measures for improving driver skill is driver training. From common sense, skill training has normally been 
regarded as an effective means of improving safety. However, very few studies have proved the correctness of this assumption. On the contrary, many studies presented in the scientific literature have failed to demonstrate a positive effect on safety (Gregersen 1994 for an overview).

There are several possible explanations of why it is so difficult to identify accident reducing effects. One such explanation is that many evaluation studies are based on a weak design, thus lacking scientific stringency. However, it has been shown (Lund and Williams 1985) that methodologically strong studies are more likely to fail in proving effects.

Among those who believe that lack of effects may be connected in some way with training as such, there have been suggestions of side effects that work against the safety goals. One such explanation is which risk compensation concerns motivational aspects of safe driving. Another explanation is that learners overestimate the safety effects of the training programme. They believe that they can make use of what they have been taught, even if this is not the case in real traffic.

One way of reducing this problem of overestimation may be to make the driver realize that he is not as skilled as he believes. Thus, driver training should not focus only on improving driving skill, as is normally the case. It should also make the driver aware that he cannot rely on his own skill in handling a critical situation. The aim of such training is to calibrate the driver's self-assessment and to encourage them to drive with larger safety margins. To achieve such insight, it is probably insufficient to tell the driver that his skills are limited: he must realize this in practice. If not, he will probably refuse to accept this as his problem. "It is probably true for other drivers, but not for me".

However, these suggestions have not been scientifically proved. They are partly based upon existing theories and must be tested and evaluated. At the Swedish Road and Transport Research Institute, several such studies are in progress with the aim of making young drivers or learner drivers realize their own limitations and encouraging them to drive with larger safety margins. In an experimental study at Swedish Telecom, this kind of driver training was shown to reduce accidents among occupational drivers compared to a control group. However, the strategy of the Telecom training was not compared with other training strategies (Gregersen et al. 1995).

In a study by Moe (1986b) a practical training program with the purpose of making the drivers aware of their limitations in critical situations was tested. He found that learner drivers reduced their high evaluation of their own skills after the insight training. The study by Moe did not include any comparison group, but was based on subjective evaluations of the learner drivers. The results did, however, indicate that the insight training strategy may reduce the level of overestimation, which supports the hypothesis that overestimation may partly be an effect of training.

\section{A I MS}

The basic assumption for this experimental study is that training strategies must be developed that reduce the probability of overestimation without jeopardizing driving ability. In the experiment, the first step has been to test this assumption.

As a first step in verifying the assumptions and suggestions mentioned above, the experiment has sought to compare how different strategies for driver training influence the overestimation of skill among drivers. Two kinds of driver training strategies are compared. One is traditional, where the purpose is only to improve the driver's skill in braking and avoidance manoeuvering. The other is to make the driver realize that his ability to handle the same kind of situation is limited.

It is natural to expect that the group with skill training will actually be more skilled, but that is not the main purpose of the study. The most important aim is to test a hypothesis of overestimation. To what degree do the drivers demonstrate correct and realistic estimation of their skill? Following the suggestions above, the main hypothesis is that the drivers with skill training overestimate their skill more than the drivers with insight training, owing to unrealistic over-confidence. Two secondary hypotheses that are also tested state that (1) the drivers with skill training will objectively be more skilled than the drivers with insight training and (2) the drivers with skill training will subjectively believe that they are more skilled than the drivers with insight training.

\section{MATERIAL AND METHODS}

The study was carried out as an experiment on a closed driving practice area for skid training. Two groups were used. One was trained to improve its skill and one was given insight into its own limitations.

\section{Experiment subjects}

A total of 58 learner drivers aged 18-24 took part in the experiment. The drivers were attending driving schools in the town of Nynäshamn and in Stockholm. They were all close to taking the driving 
test, but they had not yet passed the mandatory skid training course.

Following a conventional table of random numbers, the learner drivers were divided into two groups named "insight" $(n=30)$ and "skill" $(n=28)$. Five of the drivers did not show up as agreed, which resulted in 29 drivers in the "insight" group and 24 in the "skill" group. The experiment consisted of two parts: training and testing. Testing took place 1 week after training.

Training was carried out with "Skid Car" skid simulation equipment mounted under a car (Fig. 2). The system allows the friction of the wheels to be varied separately on each wheel while driving. "Skid Car" is used at several driving practice areas for mandatory skid training in Swedish driver training. The practice area was equipped according to Fig. 3.

Training was carried out with low friction thus making the difference between the two strategies more obvious and the effects more dramatic. The drivers in both groups drove over the same course. After accelerating to a predetermined speed, the driver passed a detector sending a radio signal to an obstacle, where a lamp was lit either on the left or the right hand side, indicating which side the driver should choose. Left/right selection was determined randomly by an integrated circuit programmed for $50-50 \%$. The distance from the detector to the obstacle was $50 \mathrm{~m}$. The calibration of the Skid Car and the distance was chosen on the basis of pre-tests in which the friction coefficient between the car and the surface was set to $0.25(55 \mathrm{~m}$ braking distance at $60 \mathrm{~km} / \mathrm{h})$. The obstacle was a rubber-covered polyester block measuring $1.5 \times 1.2 \times 0.6 \mathrm{~m}$ and mounted on wheels. The radio receiver, a battery and the lamps were built into the polyester block (Fig. 4).

Both groups were briefly introduced to the basic theory of driving on icy roads and braking and avoidance manoeuvering. Before the practical part of the session, the instructor drove the learner around the track to familiarize him with the training environment.

The practical training of the "skill" group was designed as follows: during a period of $30 \mathrm{~min}$, the driver learns how to handle a critical situation by using braking and avoidance manoeuvering. The learner drove repeatedly around the same course and increased his speed successively from about 40 to $60 \mathrm{~km} / \mathrm{h}$. The purpose was to make the learner handle the situation at $60 \mathrm{~km} / \mathrm{h}$. The instructor in the passenger seat gave instructions on how to handle the situation.

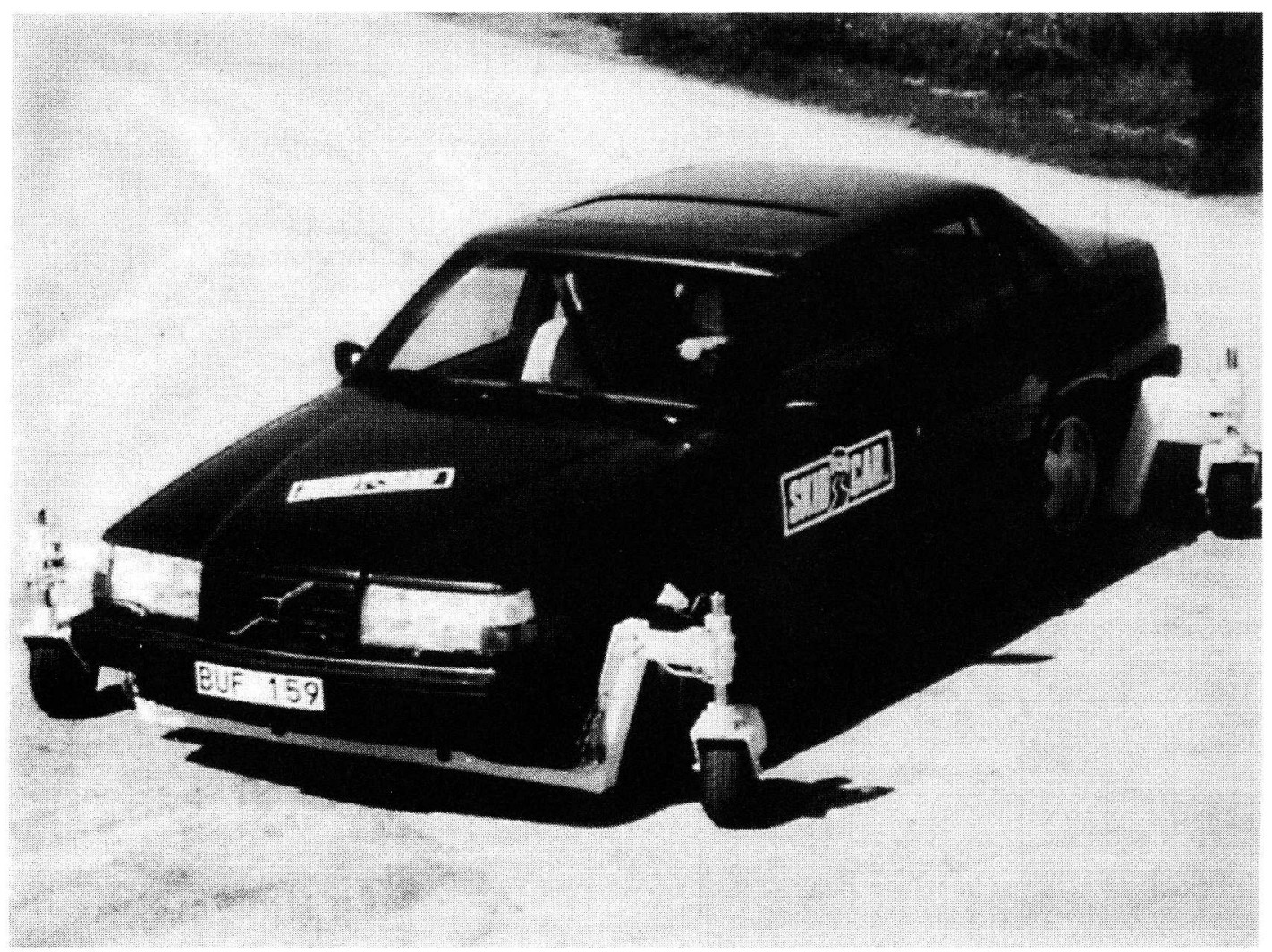

Fig. 2. The "Skid Car" used for skid simulation. 
Blad 1

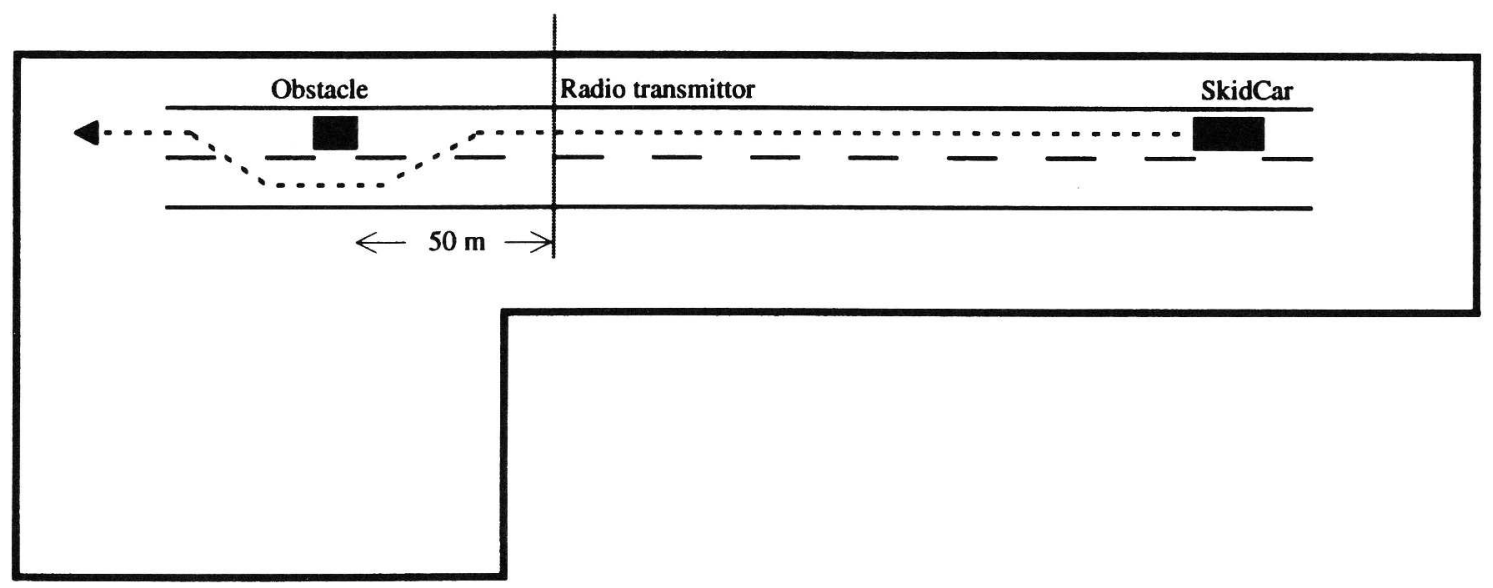

Fig. 3. The driving practice area and experimental equipment.

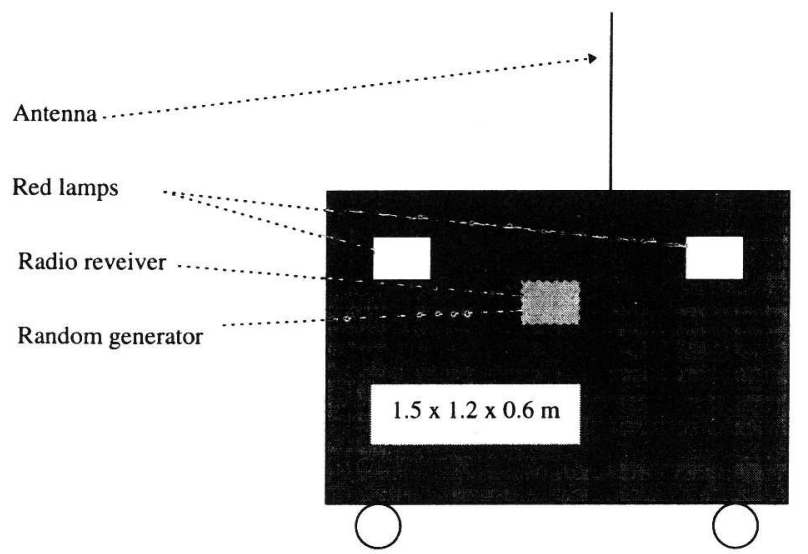

Fig. 4. Design of the obstacle.

The message to the learner was that he had received a certain amount of basic knowledge on how to handle the braking and avoidance situation.

The "insight" group drove for an equally long period, $30 \mathrm{~min}$. The design of the course was the same. However, the drivers in this group were not instructed on how to operate pedals etc. while driving, but were rather left "on their own" to decide what to do. The comments from the instructor were focused on how suddenly obstacles appear and how difficult it is to handle them. They were expected to fail in their manoeuvre at $60 \mathrm{~km} / \mathrm{h}$.

The message to these drivers was that even if they knew the basic theory of braking and avoidance, they could not rely on making use of this knowledge in a critical situation.

\section{The test}

One week after training, the learner drivers were tested. The test consisted of two tasks, the first of which was to estimate how many out of five trials of braking and avoidance in the same situation as in the training part, they believed they could manage correctly at $70 \mathrm{~km} / \mathrm{h}$. The same equipment as in the training part was used. The estimation process was followed by the second task, in which the drivers were told to drive and the actual numbers of failures and successes were counted. The outcome was classified in three classes:

(1) Successful braking and avoidance, remaining on the course after the obstacle.

(2) Avoiding the obstacle, but failing to stay on the course after the obstacle.

(3) Running into the obstacle.

Classes 2 and 3 were added and classified as failures in the analysis. During the test, the instructor accompanied the learner driver in the car, monitoring his speed. If the $70 \mathrm{~km} / \mathrm{h}$ level was not reached in any trial, an extra trial was added. This occurred three times in the "skill" group and four times in the "insight" group. Extra trials were also added on two occasions, one in each group, due to technical failures in the radio transmitter.

The following data were collected in the experiment: (a) result of each trial during the test; (b) estimated number of successful trials during the test.

The hypotheses were tested with a $t$-test and the learning effect during the test phase was analysed with ANOVA for repeated measures. The level of significance was set to 0.05 .

\section{RESULTS}

The main results are based on data from subjective estimation and the actual number of successful braking and avoidance manoeuvres. 
Figure 5 shows the distribution of estimated skill and Fig. 6 the actual skill. The "skill" group had a higher subjective estimation of their capability of handling the situation. The difference is significant $(p<0.01)$ and the hypothesis of higher subjective skill is accepted. However, for the objective "actually observed skill", no difference between the two groups was found $(p>0.4)$. The hypothesis of higher objective skill in the "skill" group is thus rejected.

Figure 7 shows the difference between subjective and objective skill. This difference is calculated by subtracting the actual number of successful trials from the estimated number. The difference between the two groups was found to be significant $(p<0.05)$, thus accepting the main hypothesis, that the drivers with

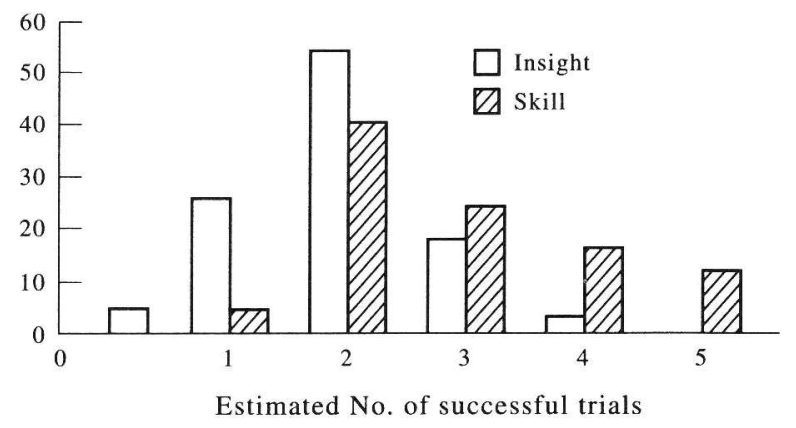

Fig. 5. Estimated number of successful trials in experimental and control groups. $x^{\prime} m_{\text {insight }}=2.0, x^{\prime} m_{\text {skill }}=2.8(p<0.01)$.

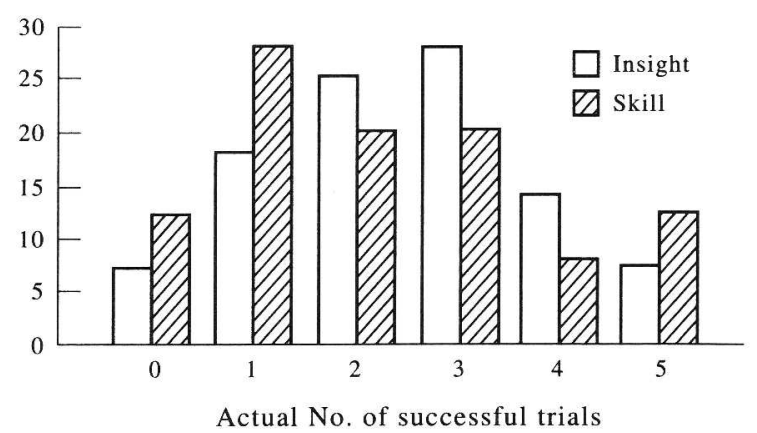

Fig. 6. Observed number of successful trials in experiment and control groups $x^{\prime} m_{\text {insight }}=2.5, x^{\prime} m_{\text {skill }}=2.2(p>0.4)$.

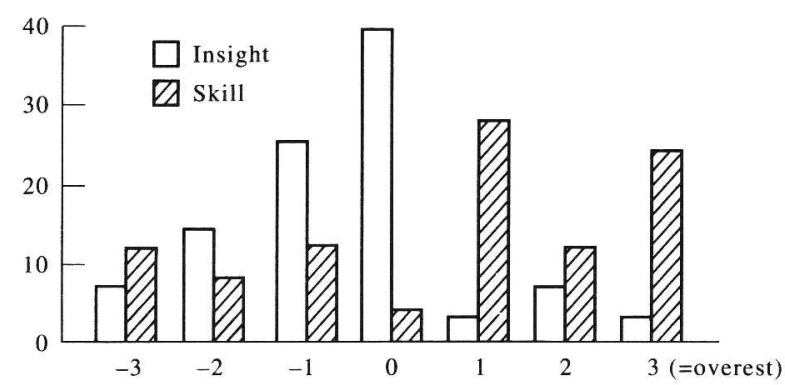

Estimated minus actual No. of successful trials

Fig. 7. Difference between estimated and observed skill in experiment and control groups. $x^{\prime} m_{\text {insight }}=0.5, x^{\prime} m_{\text {skill }}=0.7(p<0.05)$.

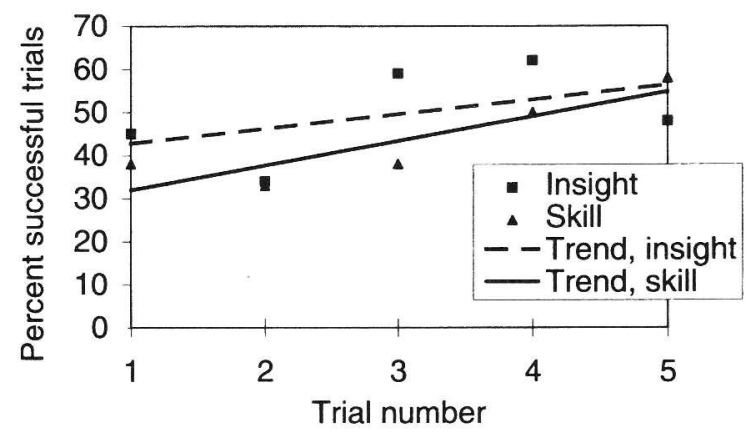

Fig. 8. Learning effects during the test, Percentage of the learners with successful trials (ns, $p>0.4$ ).

skill training overestimate their capabilities more than the drivers with insight training.

\section{Learning effects during the test}

It is reasonable to assume that the learners did learn how to avoid the obstacle during the five test runs. This has been measured by recording the order of failures and successes. Figure 8 shows the distribution of successful results over the five trials for the two groups. The results indicate that there are learning effects, but an ANOVA test for repeated measures did not show any differences in such effects between the groups.

\section{DISCUSSION}

The design of the study was experimental, with random distribution of the learners. However, since the experiment was carried out in several sessions at a driving practice area, it has not been possible to control every factor such as weather conditions. As in all field experiments, it must be remembered that such aspects may influence the results.

A limitation of the study is that the training is carried out under artificial circumstances. The "Skid Car" equipment may be regarded by some drivers as unrealistic and thus influence their estimation of ability in the test phase. Real skid training in Swedish driver training is, however, often carried out by using this equipment, which makes the experiment equivalent with real training principles. It has also been shown that the "Skid Car" is very true to real ice situations both through physical measurements and through evaluations by experienced drivers (Laurell et al. 1985).

The experiment was based on two assumptions. One is that there is an overestimation aspect of driver behaviour and the other is that overestimation may partly be an effect of the way the drivers are taught to drive. If a driver is taught only to be skilled, he may believe that he can handle situations better than 
he really can. If he is taught that he should not always rely on his skills and that he should be aware of his own limitations, the overestimation will be lower.

The findings support the idea that there is a relation between training strategies and the level of overestimation, which will probably be of great importance for the development of driver training. From a theoretical point of view, the results also support the assumption that there is an overestimation aspect of driver behaviour. The overestimation has earlier been shown basically through questionnaire studies, but this experiment suggests that these questionnaire findings are essential.

The experiment has also shown that real skill does not differ greatly between the groups. These findings may be interpreted in different ways. One explanation is that a short skill training period of half an hour does not have more potential for improving real skill than just becoming familiar with the feeling of driving on "ice". Thus the effect ought to be as we found, a similar level of actual skill in both groups.

Together, these findings may very well explain why there is an inadequate accident reducing effect of many driver training programmes. From tradition and common sense, it has been assumed that increased skill is equivalent to increased safety. This assumption is deeply anchored in people's minds and has influenced the design of driver training over many years. It is not until the last 10 years that we have started to worry about the conflicts between skill and safety. This has been discussed earlier, but the process of acceptance is very long and tradition is difficult to change. If it is accepted that skill training may lead to overestimation, it is obvious that traditions in driver training must be changed or complemented.

When interpreting the results, it is important to notice that no real control group without any driver training at all was involved in the experiment. Thus we do not know the uninfluenced level of skill or selfassessment, nor whether the two training strategies increase or decrease the actual skill or self-assessment compared to the situation before training. This may be an interesting hypothesis for further research.

For practical training development, the findings can be used in different ways. The results in themselves do not indicate how training programmes should be designed, but they do provide some important suggestions. One is that skill training may be complemented or even exchanged for insight training. The results do not say that all types of skill training produce overestimation. This has so far only been shown for this specific type of driving task on low friction, but based on many empirical studies on overestimation described in the introduction, and on the theory of
Näätänen and Summala concerning individual ability to adjust driving behaviour to the actual risk level, there is a more general problem that is probably relevant for many different situations in traffic, and where the conclusions from this experiment may prove to be true. The idea of shifting the focus from skill training to insight training may thus prove interesting in several other situations as well. In the study by Moe (1986b) where a similar strategy was used, he found even more dramatic conclusions among the learner drivers from insight training on dry roads than on simulated icy roads with the Skid Car.

It is obvious that a car driver needs skill to be able to drive the car at all. However, the level of this basic skill, the relations between different levels of skill and self-assessment and the way in which the necessary skill should be learned, are not clear. There are several important aspects of this learning process that ought to be investigated further, such as differences between skill acquisition through training courses and through long-term experience. Skill training may also be effective from a safety point of view if it is combined with insight training, to make the driver aware of the practical limitations of the skills he has learned. More development and evaluation are, however, needed.

One conclusion from this study is that the importance of overestimation should not be underestimated. Further development and research is recommended with the focus on how actual skill and overestimation relate to different strategies for driver training.

Acknowledgements-This experiment is part of a research programme on educational methods for skid training. The main sponsors of the program have been the Swedish National Road Administration, the National Society for Road Safety (NTF), the Nordic Committee for Traffic Safety Research (NKT) and the Swedish Transport and Communication Research Board (KFB).

\section{REFERENCES}

Benda, H. V.; Hoyos, C. G. Estimating hazards in traffic situations. Accid. Anal. Prev. 15:1-9; 1983.

Evans, L.; Wasielewsky, P. O. Risky driving related to driver and vehicle characteristics. Accid. Anal. Prev. 15:121-136; 1983.

Evans, L.; Wasielewsky, P. O.; von Buseck, C. R. Compulsory seat belt usage and driver risk taking behaviour. Human Factors 24:41-48; 1982.

Fhanér, G.; Hane, M. Seat belts: Factors influencing their use. A literature survey. Accid. Anal. Prev. 5:27-43; 1973.

Finn, P.; Bragg, B. W. E. Perception of the risk of an accident by young and older drivers. Accid. Anal. Prev. 18:289-298; 1986.

Galin, D. Speeds on two-lane rural roads: A multiple regression analysis. Traffic Engng Control, Aug-Sept: 453-460; 1981.

Gregersen, N. P. Integrated driver education. An experiment 
with systematic co-operation between traffic schools and private teachers (in Swedish). VTI Rapport 376. Linköping: Swedish Road and Transport Research Institute; 1993.

Gregersen, N. P. Systematic co-operation between driving schools and parents in driver education, an experiment. Accid. Anal. Prev. 26:453-461; 1994.

Gregersen, N. P.; Bjurulf, P. Young novice drivers: towards a model of their accident involvement. Accid. Anal. Prev. 28:229-241; 1996

Gregersen, N. P.; Morén, B.; Brehmer, B. Road safety improvement in large companies. An experimental comparison between different measures. Accid. Anal. Prev. 1996; In press.

Jonah, B. A. Accident risk and driver risk-taking behaviour among young drivers. Accid. Anal. Prev. 18:255-271; 1986.

Koneci, C.; Ebbesen, E. B.; Koneci, D. K. Decision processes and risk-taking in traffic: Driver response to the onset of yellow light. J. Appl. Psychol. 6:359-367; 1976.

Lacko, P.; Nilsson, G. Seat belt usage in Sweden 1983-1986 (in Swedish). VTI Rapport 326, Linköping: Swedish Road and Transport Research Institute; 1988.

Lalonde, K. G. The grande record study of motor vehicle collisions in Ontario, Toronto, Ontario: Ontario Ministry of Transportation and Communications; 1979.

Laurell, H.; Olausson, M.; Sörensen, H.; Törnros, J. Evaluation of a vehicle carrying device for simulation of low friction-SkidCar (in Swedish). VTI Rapport 290, Linköping: Swedish Road and Transport Research Institute; 1985

Lund, A. K.; Williams, A. F. A review of the literature evaluating the Defensive Driving Course. Accid. Anal. Prev. 17:449-460; 1985.

Matthews, M. L.; Moran, A. R. Age differences in male drivers' perception of accident risk: The role of perceived driving ability. Accid. Anal. Prev. 18:299-314; 1986.

McGormick, I. A.; Walkey, F. H.; Green, D. E. Comparative perceptions of driver ability-a confirmation and expansion. Accid. Anal. Prev. 18:205-208; 1986.

Michels, W.; Schneider, P. A. Traffic offences: Another description and prediction. Accid. Anal. Prev. 16:223-238; 1984.

Moe, D. Young drivers. Relation between perceived and real ability (in Norwegian). TFD Report 1984:5. Stockholm: Swedish Transport and Communication Research Board; 1984.

Moe, D. Young drivers. Relation between perceived and real ability, behaviour studies (in Norwegian). TFB Report 1986:17. Stockholm: Swedish Transport and Communication Research Board; 1986a.

Moe, D. The UNI-car-High speed training in critical situations on dry and simulated icy surface (in Norwegian). SINTEF Rapport STF 63 A86026, Tronheim: SINTEF; 1986 b.

Nolén, $\mathrm{S}$. Is there any relation between the driver's experience, attitudes and beliefs and his/her use of seat belts? (in Swedish) VTI Rapport 338. Linköping: Swedish Road and Transport Research Institute; 1988.

Quimby, A. R.; Watts, G. R. Human factor and driving performance. LR 1004. Crowthorne: Transport Research Laboratory; 1981.

Spolander, K. Drivers' assessment of their own driving ability (in Swedish) VTI Rapport 252. Linköping: Swedish Road and Transport Research Institute; 1983.

Svenson, $O$. Are we all less risky and more skilful than our fellow drivers? Acta Psychol. 47:143-148; 1981.

Wasielewsky, P. Speed as a measure of driver risk: observed speeds versus driver and vehicle characteristics. Accid. Anal. Prev. 16:89-104; 1984.

Wilde, G. J. S. The theory of risk homeostasis: Implications for safety and health. Risk Analysis 2:209-258; 1982.

Wilson, R. J. A national household survey on drinking and driving: Knowledge, attitudes and behaviour of Canadian drivers. TMRU 8402, Road Safety Directorate, Transport Canada; 1984. 




\section{di}

$\frac{\text { Swedish National Road and }}{\text { Transport Research Institute }}$

The Swedish Road and Transport Research Institute has laboratories and know-how for advanced research commissions in transport and welfare economics, road safety, vehicles and the environment. It also has research capabilities for the construction, operation and maintenance of roads and railways.

Address

S-581 95 Linköping

Sweden 